\title{
The Relationship Of Smoking Behavior Towards Decreased Appetite (Anorexia) In S1 Nursing Students Stikes Yahyha Bima
}

\author{
Ayatullah \\ Ayatullah92@yahoo.com, \\ STIKES YAHYA BIMA \\ NIDN. 0812099201
}

\begin{abstract}
Smoking behavior is a related issue public health because it can cause various diseases even can cause death for both smokers and people nearby (passive smokers). The purpose of this study was to determine the relationship of smoking behavior to decreased appetite (anorexia). This research is a type of Descriptive Analytical research with Cross Sectional method, the population in this study is the student of S1 undergraduate of Nursing STIKES Yahya Bima in 2017. Sampling using Total Sampling Technique, obtained 50 respondents. The data were collected by using Questionnaire. Data that has been collected and then processed and analyzed using computer program Microsoft Exeldan Statistic program (SPSS) version 16.0. Data analysis included univariate analysis by finding frequency distribution, bivariate analysis with Chi-Square test $(p<0,05)$ to know relation between variable and person test to know correlation strength. The result of bivariate analysis showed the correlation between smoking behavior and decreased appetite $(p=0.125<0,05)$. The conclusion in this research is there is no correlation between smoking behavior with decreasing appetite in student of S1 Nursing STIKES Yahya Bima. It is recommended for male students STIKES Yahya Bima to change smoking behavior because it will affect health especially on respiratory system, rubalah healthy lifestyle with exercise and achievement. For nursing profession is expected to always promote healthy lifestyle without cigarette smoke
\end{abstract}

Keywords: Smoking Behavior, Anorexia, Eat Frequency. 


\title{
Hubungan Perilaku Merokok Terhadap Penurunan Nafsu Makan (Anoreksia) Pada Mahasiswa S1 Keperawatan Stikes Yahya Bima
}

\begin{abstract}
Abstrak: Perilaku merokok merupakan masalah yang berkaitan dengan kesehatan masyarakat karena dapat menimbulkan berbagai penyakit bahkan dapat menyebabkan kematian baik bagi perokok dan orang yang ada disekitarnya (perokok pasif). Tujuan penelitian ini adalah untuk mengetahui hubungan perilaku merokok terhadap penurunan nafsu makan (anoreksia). Penelitian ini merupakan jenis penelitian Deskriptif Analitikdengan metode Cross Sectional, populasi dalam penelitian ini adalah mahasiswa laki-laki S1 Keperawatan STIKES Yahya Bima tahun 2017. Pengambilan sampel menggunakan Tebnik Total Sampling, didapatkan 50 responden. Pengumpulan data dilakukan dengan menggunakan Kuesioner. Data yang telah terkumpul kemudian diolah dan dianalisis dengan menggunakan computer program Microsoft Exeldan program Statistic (SPSS) versi 16.0. Analisis data mencakup analisis univariat dengan mencari distribusi frekuensi, analisis bivariat dengan uji Chi-Square $(\mathrm{p}<0,05)$ untuk mengetahui hubungan antar variabel dan uji person untuk mengetahui kekuatan korelasi. Hasil analisis bivariat didapatkan hubungan antara perilaku merokok dengan penurunan nafsu makan $(p=0.125<0,05)$. Kesimpulan dalam penelitian ini adalah tidak ada hubungan antara perilaku merokok dengan penurunan nafsu makan pada mahasiswa S1 Keperawatan STIKES Yahya Bima. Disarankan bagi mahasiswa laki-laki STIKES Yahya Bima agar merubah perilaku merokok karna akan mempengaruhi kesehatan terutama pada sistem pernafasan, rubalah pola hidup sehat dengan berolah raga dan berprestasi.Bagi profesi keperawatan diharapkan agar selalu mempromosikan gaya hidup sehat tanpa asap rokok.
\end{abstract}

Kata kunci : Perilaku Merokok, Anoreksia, Nafsu Makan.

\section{Pendahuluan}

Perilaku merokok merupakan masalah yang berkaitan dengan kesehatan masyarakat karena dapat menimbulkan berbagai penyakit bahkan dapat menyebabkan kematian baik bagi perokok dan orang yang ada disekitarnya (perokok pasif). Setiap orang telah mengetahui bahwa merokok adalah berbahaya bagi kesehatan, namun pada kenyataanya perilaku merokok 
masih sangat sulit untuk dikendalikan. Merokok juga dapat menjadi awal bagi seseorang untuk mencoba berbagai zat adiktif yang lainnya, karena bagi seorang perokok lebih mudah untuk mencoba zat-zat adiktif yang lain tersebut daripada bukan seorang perokok (Wismanto, 2007). "Merokok dapat menyebabkan kanker, serangan jantung, impotensi, gangguan kehamilan dan janin." Pesan ini tertera dalam setiap bungkus rokok, dan meskipun masih tergolong baru, sekarang ini perigatan bahaya rokok berupa gambar penyakit akibat merokok yang terdapat pada kemasan rokok sudah diterapkan di Indonesia. Namun pada kenyataannya, perilaku merokok masyarakat masih sangat sulit untuk dikendalikan.

Berdasarkan data WHO (2013), prevalensi penduduk usia dewasa yang merokok setiap hari di Indonesia sebesar 29\% sehingga Indonesia menempati urutanpertama se-Asia Tenggara dalam hal jumlah perokok. Sedangkan di dunia, Indonesia menempati urutan ketiga dalam hal jumlah perokok setelah Cina dan India dengan prevalensi perokok sebesar 36,1\% Global Adults Tobacco Survey (GATS, 2011). Berdasarkan data WHO (2012), sebanyak 67\% dari semua pria di Indonesia yang berusia lebih dari 15 tahun merupakan perokok aktif. Dua dari tiga pria di Indonesia memiliki kebiasaan merokok. Sementara sekitar 3\% perempuan Indonesia jugaperokok. Berdasarkan data Global Adults Tobacco Survey (2011), Indonesia memiliki jumlah perokok aktif terbanyak dengan prevalensi perokok laki laki sebesar 67\% (57,6 juta) dan prevalensi perokok wanita sebesar 2,7\% (2,3 juta). Angka kematian akibat penyakit tidak menular yang berhubungan dengan rokok diperkirakan terus meningkat. Sedikitnya 5 juta orang meninggal di seluruh dunia akibat penyakit yang disebabkan oleh tembakau setiap tahunnya. Jumlah ini dikhawatirkan akan mencapai 10 juta pertahun pada tahun 2030 dimana $70 \%$ kematian terjadi di negara-negara berkembang (WHO, 2012). Data tersebut juga menyebutkan bahwa penyakit yang terkait merokok membunuh paling sedikit 200.000 orang setiap tahun di Indonesia.

Prilaku merokok di kalangan remaja sekarang bukan hal yang baru lagi, Indonesia tercatat sebagai Negara dengan jumlah perokok remaja terbesar di dunia (Pramasari, 2008 \&Ismarwati, 2012).

Menurut Iqbal presentasi tertinggi seseorang mulai merokok adalah pada usia 16-20 tahun, yaitu sebesar 53,1\% dimana usia tersebut menandakan individu yang bersangkutan sedang dalam masa remaja. DiNusa Tenggara Barat(NTB) sekitar 2,3\% penduduk usia 10-14 tahun adalah perokok, 0,9\% diantaranya merokok setiap hari dan 1,5\% perokok kadang-kadang. Sekitar 1,6\% perokok usia 10-14 tahun mulai merokok setiap hari pada usia 5-9 tahun dan 19\% mulai pada usia 10-14 tahun (Rahmat,2013).

Dari data di atas kelompok umur yang paling banyak merokok adalah remaja.Masa remaja merupakan masa peralihan dari masa kanak-kanak ke masa 
dewasa dan terjadi perubahan fisik yang cepat menyamai orang dewasa, tetapi emosinya belum tentu mengikuti perkembangan jasmaninya. Menurut Hurlock (1998) dan putri (2010) setiap periode tumbuh kembang mempunyai tahapan tersendiri, namun masa remaja sering menjadi masalah yang sulit diatasi oleh anak laki-laki maupun anak perempuan. Kesulitan pertama, masalah anak yang sebagian besar diselesaikan oleh orang tua dan guru mengakibatka remaja tidak berpengalaman dalam mengatasinnya. Kedua, karena remaja mersa telah mandiri, sehingga mereka ingin mengatasi masalahnya sendiri, menolak bantuan orang tua. Sedangkan menurut Suryanah (1996) dalam putri (2010) masalah dikalangan remaja yang banyak terjadi antara lain ketergantungan obat, ketergantungan alcohol, dan kertergantungan terhadap rokok. (Elok Nuradita, 2012)

Semakin banyak orang mengkonsumsi rokok, maka semakin tinggi juga Nikotin yang ada pada orang tersebut dan bahaya merokok salah satunya adalah penurunan nafsu makan dan penurunan nafsu makan di sini disebabkan karena kandungan yang ada di rokok itu mengandung Nikotin. Nikotin pada bermacam penelitian telah terbukti menyebabkan penurunan nafsu makan dan asupan makanan serta meningkatkan laju metabolisme tubuh. Perbedaan IMT pada perokok dan bukan perokok dapat terlihat $(4-5 \mathrm{~kg})$. Telah diketahui dari penelitian - penelitian sebelumnya bahwa IMT perokok akan lebih rendah dari bukan perokok.

Nikotin berperan dalam penekan nafsu lapar, meningkatkan energi ekspenditur dengan peningkatan dari laju metabolisme dan dalam keadaan kronis dari pemakaian nikotin maka dapat berdampak pada perubahan indeks massa tubuh. Nikotin memicu pelepasan glutamat, yang memfasilitasi pelepasan dopamin dan GABA yang berfungsi sebagai inhibator dalam pelepasan dopamin. Terpapar nikotin dalam waktu yang lama akan menyebakan beberapa reseptor nikotinik kolinergik menjadi desentisisasi, pada kasus ini GABA terdensensitiasi dan glutamat terus dilepas sehingga menyebabkan respon terhadap nikotin meningkat. Oleh karena itu dapat mengakibatkan seseorang dapat menunda dari laparnya tersebut, rela tidak makan selama 12 jam penuh karena rokok dapat membuat seseorang tersebut tersambung pada reseptor di otak untuk tidak makan, bahkan mengakibatkan kekurangan gizi, serta tidak diketahui terdapat kanker dalam tubuh yang tidak dirasa yang membuat berat badan turus drastis. (Hari Nugrobo, 2014)

Di Bima, sekitar 23\% penduduk saat ini merokok dengan rata konsumsi 11,6 batang per hari. Dari jumlah perokok tersebut, sekitar 2,3\% berusia 10-14 tahun dengan rata konsumsi rokok 5,3 batang per-hari. Sekitar $0,9 \%$ mulai merokok setiap pada usia 5-9 tahun dan 7,8\% pada usia 10-14 tahun. Bahkan sekitar 2,7\% mulai merokok pada usia 5-9 tahun. (Rachmat, 2013).

Berdasarkan data yang di ambil dari Prodi S1 keperawatan Sekolah Tinggi Ilmu Kesehatan Stikes Yahya Bima, jumlah mahasiswa laki-laki semester II sebanyak 13 orang, 8 orang adalah perokok aktif dan 5 orang bukan perokok, semester IV sebanyak 14orang, 10 orang adalah perokok aktif dan 4 orang bukan 
perokok, Semester VI sebanyak 14 orang, 11 orang adalah perokok aktif dan 3 orang bukan perokok, dan semester VIII sebanyak 9 orang, dan semuanya perokok aktif dari Ada 50mahasiswa laki - laki yang merokok kurang lebih 1 tahun dan banyak mahasiswa perokok yang mengatakan jika mereka merokok mereka sudah merasa kenyang dan ada pula mahasiswa yang mengatakan mereka lebih memilih merokok dari pada makan.

\section{Metode Penelitian}

Penelitian yang digunakan penelitian adalah penelitianNon-eksperimen. Jenis penelitian yang digunakan adalah Deskriptif Analitikdengan menggunakan rancangan Cros-Sectional, dimana semua variabel penelitian diukur dalam periode waktu yang bersamaan.Penelitian ini dilaksanakan di Sekolah Tinggi Ilmu Kesehatan STIKES Yahya Bima Nusa Tenggara Barat.Sampel dalam penelitian ini adalah Mahasiswa lakilaki S1 Keperawatan Stikes Yahya Bima.Penelitian ini menggunakan Total Sampling, Yaitu teknik penetapan sampel dengan cara memilih sampel di antara populasi sesuai dengan yang dikehendaki peneliti.

\section{Hasil Penelitian}

1. AnalisisUnivariat

a. KarateristikUmumResponden

Berdasarkanhasilpenelitian yang dilakukan di STIKES Yahya Bima dengan 30responden diperoleh data sebagai berikut:

(1) Distribusi jenis kelamin responden.

Tabel 5.1

Distribusi Frekuensi Responden Berdasarkan Jenis Kelamin Mahasiswa STIKES Yahya Bima

\begin{tabular}{|c|l|l|l|}
\hline No & Jenis Kelamin & Frekuensi & $\mathbf{0}$ \\
\hline 1 & Laki-laki & 30 & $100 \%$ \\
\hline 2 & Perempuan & 0 & $0 \%$ \\
\hline 3 & Jumlah & 30 & $100 \%$ \\
\hline
\end{tabular}

Sumber : Data Primer Agustus 2017

Table 5.1 tentang distribusi responden berdasarkan jenis kelamin mahasiswa STIKES Yahya Bima yang merokok,dari 30 responden menunjukkan yang berjenis kelamin laki-laki sebanyak 30 orang $(100 \%)$ dan tidak ada yang berjenis kelamin perempuan.

(2) Distribusi jurusan responden. 
Tabel 5.2

Distribusi Responden Berdasarkan Jurusan Mahasiswa STIKES Yahya Bima Yang

Merokok

\begin{tabular}{|l|l|l|l|}
\hline No. & Jurusan & Frekuensi & $\mathbf{\%}$ \\
\hline 1 & Keperawatan & 30 & 100 \\
\hline 2 & Kebidanan & 0 & 0 \\
\hline 3 & Jumlah & 30 & 100 \\
\hline
\end{tabular}

Sumber : Data Primer Agustus 2017

Tabel 5.2 tentang distribusi responden berdasarkan jurusan mahasiswa STIKES Yahya Bima yang merokok, dari 30 responden menunjukkan bahwa yang mengambil jurusan keperawatan ada 30 orang $(100 \%)$ dan tidak ada yang mengambil jurusan kebidanan $(0 \%)$.

(3) Distribusi Frekuensi Analisis Univariat.

Analisis univariat dilakukan terhadap tiap variabel-variabel penelitian. Padaanalisisiniakanmenghasilkandistribusifrekuensidaritiapvariabel-variabel yang berhubungan. Adapun variabel-variabel yang dianalisis yaitu :

(a) Distribusi Frekuensi Responden Berdasarkan Perilaku Merokok.

Tabel 5.3

Distribusi Frekuensi Responden Berdasarkan PerilakuMerokok Mahasiswa STIKES Yahya Bima

\begin{tabular}{|l|l|l|l|}
\hline No & Perilaku merokok & Frekuensi & $\mathbf{0}$ \\
\hline 1 & Aktif & 18 & $60 \%$ \\
\hline 2 & Pasif & 12 & $40 \%$ \\
\hline 3 & Jumlah & 30 & $100 \%$ \\
\hline
\end{tabular}

Sumber : Data Primer Agustus 2017

Tabel 5.3 tentang distribusi responden berdasarkan perilaku merokok mahasiswa di Stikes Yahya Bima, bahwa dari 30 orang responden yang perokok aktif ada 18 orang (60\%) sedangkan yang perokok pasif ada 12 orang $(40 \%)$.

(b) Distribusi Frekuensi Responden Berdasarkan Penurunan Nafsu Makan.

Tabel 5.4

Distribusi Frekuensi Responden Berdasarkan Penurunan Nafsu Makan Mahasiswa di Stikes Yahya Bima

\begin{tabular}{|l|l|l|l|}
\hline No & $\begin{array}{l}\text { Penurunan Nafsu } \\
\text { Makan }\end{array}$ & Frekuensi & $\mathbf{\%}$ \\
\hline 1 & Menurun & 4 & $13,3 \%$ \\
\hline 2 & Tudak menurun & 26 & $86,7 \%$ \\
\hline 3 & Jumlah & 30 & $100 \%$ \\
\hline
\end{tabular}


Sumber : Data Primer Agustus 2017

Table 5.4 tentang distribusi responden berdasarkan penurunan nafsu makan, dari 30 responden menunjukan bahwa responden yang nafsu makannya menurun sebanyak 4 orang $(13,3 \%)$ sedangkan yang nafsu makannya tidak menurun sebanyak 26 orang $(86,7 \%)$.

2. Analisis Bivariat.

Analisisbivariatiniuntukmelihatapakahadahubunganantaravariableindepende ndenganvariable dependen.Hubunganiniakanterlihatdari $\mathrm{p}$ value yang akandihasilkandari table analisis SPSS 16. DigunakanujistatisticChiSquaredengantingkatkemaknaan $\alpha=0,05$ atau interval kepercayaan $\mathrm{p}<0,05$.

a. Hubungan Perilaku Merokok Terhadap Penurunan Nafsu Makan

Tabel 5.5 Hubungan Perilaku Merokok Dengan Penurunan Nafsu Makan Mahasiswa di Stikes Yahya Bima

\begin{tabular}{|c|c|c|c|c|c|c|c|}
\hline \multirow{3}{*}{$\begin{array}{l}\text { Perilaku } \\
\text { Merokok }\end{array}$} & \multicolumn{4}{|c|}{ Penurunan Nafsu Makan } & & & \multirow{3}{*}{$p$} \\
\hline & \multicolumn{2}{|c|}{ Menurun } & \multicolumn{2}{|c|}{$\begin{array}{l}\text { Tidak } \\
\text { Menurun }\end{array}$} & \multicolumn{2}{|c|}{ Jumlah } & \\
\hline & $\mathrm{N}$ & $\%$ & $\mathrm{~N}$ & $\%$ & $\mathrm{~N}$ & $\%$ & \\
\hline Aktif & 1 & 3,3 & 17 & 56,7 & 18 & 60 & \\
\hline Pasif & 3 & 10 & 9 & 30 & 12 & 40 & 0.125 \\
\hline Jumlah & 4 & 13,3 & 26 & 86,7 & 30 & 100,0 & \\
\hline
\end{tabular}

Sumber : Data Primer Agustus 2017

Tabel 5.6 tentang distribusi responden berdasarkan perilaku merokok mahasiswa di Stikes Yahya Bima dari 18 orang $(60 \%)$ yang aktif ada 1 orang (3,3\%) nafsu makannya menurun dan ada 17 orang $(56,7 \%)$ yang nafsu makannya tidak menurun. Sedangkan dari 12 orang (40\%) yang pasif ada 3 orang $(10 \%)$ yang nafsu makannya menurun dan ada 9 orang (30\%) yang nafsu makannya tidak menurun.

Berdasarkan uji statistik Chi-squaredi peroleh nilai $\mathrm{p}=0.125$. Dengan demikian Ha ditolak dan Ho diterima atau tidak ada hubungan antara perilaku merokok dengan penurunan nafsu makan.

\section{Pembahasan}

\section{Hubungan Antara Perilaku Merokok Dengan Penurunan Nafsu Makan.}

Hasil uji statistic Chi-square pada hasil penelitian ini diperoleh bahwa tidak ada hubungan antara pengetahuan dengan kejadian malaria.Dimana $\mathrm{p}$ $=0.125>0,05$.

Hubungan tergambar pada tabel 5.6 tentang distribusi responden berdasarkan perilaku merokok mahasiswa di STIKES Yahya Bima dari 18 
orang $(60 \%)$ yang aktif ada 1 orang $(3,3 \%)$ nafsu makannya menurun dan ada 17 orang $(56,7 \%)$ yang nafsu makannya tidak menurun. Sedangkan dari 12 orang (40\%) yang pasif ada 3 orang (10\%) yang nafsu makannya menurun dan ada 9 orang (30\%) yang nafsu makannya tidak menurun.

Hal ini tidak sejalan dengan penelitian sebelumnya oleh Chiolero A. 2010 terdapat perbedaan dari indeks masa tubuh pada macam-macam perokok. Perokok dikategorikan menjadi bukan perokok (tidak pernah merokok), perokok ringan (1-9 batang / hari), perokok sedang (20-40 batang / hari), perokok berat ( $\geq 40$ batang / hari). Semakin banyak orang mengkonsumsi rokok, maka semakin tinggi juga nikotin yang ada pada orang tersebut. Nikotin berperan dalam penekan nafsu lapar, meningkatkan energi ekspenditur dengan peningkatan dari laju metabolism dan dalam keadaan kronis dari pemakaian nikotin maka dapat berdampak pada perubahan indeks massa tubuh. Nikotin pada bermacam penelitian telah terbukti menyebabkan penurunan nafsu makan dan asupan makanan serta meningkatkan laju metabolisme tubuh. Perbedaan IMT pada perokok dan bukan perokok dapat terlihat $(4-5 \mathrm{~kg})$. Telah diketahui dari penelitian penelitian sebelumnya bahwa IMT perokok akan lebih rendah dari bukan perokok.

Peneiliti menganalisis bahwa penurunan nafsu makan yang terjadi pada perokok, baik perokok aktif maupun pasif bukan serta merta disebabkan karena mahasiswa merokok, akan tetapi dilihat dari kondisi mahasiswa belum mampu dan tak ada minat untuk masak sendiri maupun factor X lain yang perlu dikaji dan bahkan dilakukan penelitian baru, untuk mengunggkap penuruna nafsu makan yang terjadi dimahasiswa.

\section{Kesimpulan}

Dari hasil penelitian di STIKES Yahya Bima pada tahun 2017 tentang hubungan perilaku merokok terhadap penurunan penurunan nafsu makan (anoreksia) pada mahasiswa S-1 keperawatan STIKES Yahya Bima tahun 2017 disimpulkan bahwa tidak ada hubungan antara perilaku merokok terhadap penurunan nafsu makan dengan $\varrho=0,125$. 


\section{Daftar Pustaka}

Aditama, Tjandra Yoga. 2011. Rokok dan kesehatan. Jakarta.

Aula, Lisa Ellizabet. 2010.Stop Merokok. Cetakan Pertama.

Ernawati, Dwi \&Ismarwati. 2012.Jurnal Kebidanan dan Keperawatan, Vol. 8, No. 2.

Hidayat, A. Aziz Alimul. 2014. Metode Penelitian Keperawatan dan Tehnik Analisa Data. Edisi Pertama. Jakarta: Salemba Medika.

Hidayat, A. Aziz Alimul. 2012.Riset Keperwatan dan Tehnik Penulisan Ilmiah, Edisi Kedua. Jakarta: Salemba Medika.

Haspari, Elina Wahyu. 2014. Unnes Journal of Public Health 3 (2).

Makara. 2013. Kesehatan, Vol. 7, NO. 2.

Mariyam, Nuradita Elok. 2013. Jurnal Keperawatan Anak. Volume 1.

Nursalam. 2014. Metodologi Penelitian Ilmu Keperawatan. Pendekatan Praktis Edisi 3. Jakarta: Salemba Medika.

Nursalam. 2011. Konsep dan Penerapan Metodologi Penelitian Ilmu Keperawatan. Jakarta: Salemba Medika.

Prabowo, Eko. 2014. Buku Ajar Keperawatan Jiwa. Cetakan Pertama.

Pudiastuti, Ratna Dewi. 2011. Penyakit Pemicu Stroke. Yogyakarta: Nuha Medika.

Prasetyo, Lukyta Dwi. 2011. Jurnal Pengaruh Negatif Rokok Bagi Kesehatan di Kalangan Remaja.

Raiya, ABD. Rasyid. 2013. Faktor-Faktor yang Berbubungan Dengan Perilaku Merokok Pada Siswa SMA Kristen Soleman Makassar.

Sinurat, Evirosa Violenta. 2013. Jurnal Hubungan Antara Merokok Dengan IMT (Indeks Massa Tubub) Mahasiswa S1 Universitas Tanjungpura, Kalimantan Barat.Kalimantan Barat: Universitas Tanjung.

Tim Penulis Poltekes Depkes Jakarta 1. 2012. Kesehatan Remaja Problem dan Solusinya. Cetakan Ketiga. Jakarta: Salemba Medika.

Buku Panduan Umum. 2017. Pembuatan Dan Penulisan Proposal Skripsi STIKES YahyaBima. Bima: STIKES Yahya Bima. 